\title{
Abordagens investigativas no ensino de Química: limites e possibilidades
}

Investigative approaches in Chemistry education: limits and possibilities

\author{
Edson José Wartha ${ }^{1}$ \\ Marcos Mendonça Lemos ${ }^{2}$
}

\section{Resumo}

Este trabalho procura apresentar e discutir fundamentos teóricos e pedagógicos do ensino por investigação, procurando identificar limites e possibilidades dessa abordagem no Ensino de Ciências a partir dos documentos oficiais e de artigos que abordam a questão da abordagem investigativa no Ensino de Ciências. Os resultados apresentam inúmeras possibilidades de abordagens investigativas no Ensino de Ciências que na maioria das vezes são limitadas por aspectos relativos a formação docente.

Palavras-chave: abordagem investigativa, ensino de ciências, formação de professores.

\section{Abstract}

This work aims to present and discuss theoretical and pedagogical foundations of education for research, seeking to identify the limits and possibilities of this approach in teaching science from official documents and articles that address the issue of investigative approach to science education. The results show numerous possibilities of investigative approaches in science education that most often are limited by aspects of teacher education.

Keywords: investigative approach, science education, teacher training.

\footnotetext{
${ }^{1}$ Universidade Federal de Sergipe | ejwartha@gmail.com

2 Instituto Federal de Educação, Ciência e Tecnologia da Bahial mmlq4@hotmail.com
} 


\section{Introdução}

A abordagem investigativa sempre aparece em destaque nos documentos oficiais, como por exemplo, nas Orientações Curriculares Nacionais - PCN+ "(...) incentivar atividades de enriquecimento cultural; desenvolver práticas investigativas; elaborar e executar projetos para desenvolver conteúdos curriculares; utilizar novas metodologias, estratégias e materiais de apoio; desenvolver hábitos de colaboração e trabalho em equipe (...) (BRASIL, 2002, p. 137), nos Parâmetros Curriculares Nacionais - PCNEM ao indicar as competências e habilidades a serem desenvolvidas em química destaca a investigação e compreensão como aspectos fundamentais a serem desenvolvidos nas aulas de química (BRASIL, 1999, p. 39). E, na Base Nacional Comum Curricular (BNCC) que mesmo não estando na sua versão final continua destacando as abordagens investigativas no documento. Tal fato pode ser observado logo no início do documento, ao tratar da disciplina escolar química, em que indica que para a organização do currículo de Química, no Ensino Médio, são propostas seis unidades de conhecimento (UCQ) que remetem aos grandes temas da Química e a algumas práticas de investigação relevantes para a sociedade brasileira (BRASIL, 2016).

Assim, a questão que move e direciona as discussões neste trabalho, se dá no sentido de identificar e discutir os limites e possibilidades das abordagens investigativas no Ensino de Ciências (Química, Física, Biologia, Geociências), procurando elementos teóricos e pedagógicos que sirvam de reflexão na tentativa de compreender quais são as possibilidades e os limites para que a abordagem investigativa ocorra de fato em sala de aula. $O$ ensino por investigação ou abordagem investigativa que tem uma longa história na educação em ciência, trabalha com os estudantes na perspectiva de fomentar questionamentos, elaboração de modelos explicativos com bases em evidências e a comunicação desses modelos. Estes são processos que permitem aos estudantes aprender ciências, aprender a fazer ciências e aprender sobre ciências, mas que, por outro lado, implica em uma mudança de postura dos professores em sala de aula, pois as abordagens investigativas os levam a tomarem várias decisões, a correrem riscos, a enfrentarem dificuldades e novos dilemas (HODSON, 1994).

Abd-el-Khalick, Bell e Ledermann (1998) verificando as rotinas e práticas tradicionais do sistema educativo dos Estados Unidos da América, identificaram determinadas relações entre as concepções sobre a natureza da ciência dos professores e os aspectos pedagógicos de sua formação e consequente atuação em sala de aula. O professor não é um técnico que aplica instruções, ele constrói e processa informações, toma decisões, planeja e executa atividades, seleciona os temas e a forma de abordagem com os estudantes, mas também possui crenças ou concepções sobre a natureza das ciências e sobre o processo de ensino que podem influenciar na sua atividade profissional. Shulman (1986; 1993) considera que, além do conhecimento do conteúdo e do conhecimento pedagógico, os professores desenvolvem um conhecimento específico sobre a forma de ensinar a matéria que denomina de conhecimento pedagógico do conteúdo. Shulman (1993) considera o professor um mediador que transforma o conteúdo a ser ensinado aos estudantes em representações compreensíveis. O conhecimento que o professor tem do conteúdo de ciências está mais relacionado ao próprio processo de ensino deste conteúdo. Assim, há evidências de que aspectos relacionados à formação de professores de ciências tenham relação com o uso ou não de abordagens investigativas nas aulas de ciências. 
No estudo desenvolvido por Sá et al., (2007), além de verificarem que a abordagem investigativa ainda não está bem estabelecida no Brasil, ressaltam a dificuldade de os professores utilizarem atividades de investigação com os estudantes, por se sentirem inseguros ou por apresentarem concepções inadequadas sobre a natureza da ciência. Cachapuz (1989), afirma que o processo de investigação é uma oportunidade de o professor refletir sobre a sua prática. Assim, cabe ao professor, pesquisar metodologias que se adaptem a realidade do educando buscando promover atividades que permitam o entendimento da ciência como um processo de construção sócio histórica.

De acordo com Carvalho (2004) é necessário também, que se considere o entendimento da natureza da ciência, não como algo pronto e acabado, mas como um processo constante de construção e aprimoramento. Para esta autora uma abordagem investigativa deve permitir aos estudantes participação no processo de elaboração conceitual, dando oportunidade e condições para que argumentem e exercitem a razão, em vez de fornecer respostas prontas e acabadas contribuindo para que se tenha uma visão fechada das ciências.

Estes estudos mostram que há uma relação entre a ciência escolar e a ciência dos cientistas e que visões distorcidas sobre a natureza da ciência, podem contribuir para que os professores adotem abordagens metodológicas que reforcem tais visões. Portanto, de nosso ponto de vista, o ensino de ciências por investigação seria uma estratégia entre outras que o(a) professor(a) poderia selecionar ao procurar diversificar sua prática pedagógica de modo a mobilizar o estudante a aprender ciências, não da maneira como os cientistas fazem em seus laboratórios, mas sim, apropriando-se de práticas dos cientistas como por exemplo, a curiosidade, a dúvida, a argumentação, a explicação, o compartilhamento da ideias e a própria reformulação das ideias.

\section{Os fundamentos teóricos da abordagem investigativa}

Buscando esclarecer o conceito de abordagem investigativa, identificou-se uma diversidade de definições e de termos que apresentam o mesmo significado, mas em perspectivas diferentes. Por exemplo, alguns autores, relacionam a abordagem investigativa com a atividade científica, para outros caracteriza-se através dos processos científicos, outros associam à resolução de problemas ou ensino por descoberta e, ainda há autores que englobam mais do que uma destas perspectivas. No Brasil, nas últimas décadas vem ganhando força no meio educacional diferentes perspectivas de abordagem investigativas, como é o caso da abordagem CTS (AULER e BAZZO, 2001), a abordagem poblematizadora (DELIZOICOV, 1983) bem como a aprendizagem baseada na resolução de problemas (PEDUZZI e MORREIRA, 1981).

Aulls e Shore (2008) verificaram que na década de 60 do século passado, o termo descoberta e resolução de problemas foram os mais utilizados pelos pesquisadores educacionais. Esses autores afirmam que quando comparado com a resolução de problemas, o conceito descobrir é mais intuitivo, misterioso e parece depender mais da experiência do dia-a-dia. Por outro lado, o termo problema refere-se a uma questão que está sem resposta. Assim, os autores consideram que a resolução de problemas se apresenta mais adequado para conceituar uma abordagem investigativa ou ensino por investigação. 
Schwartz e Crawford (2006) relacionam a abordagem investigativa com a atividade científica, pois, segundo esses autores, à semelhança do que acontece em uma comunidade científica, durante o desenvolvimento de atividades de investigação, os estudantes têm oportunidade de negociar e a negociação na sala de aula durante uma atividade investigativa envolve a argumentação, a comunicação dos resultados, a troca de exemplos e a aceitação pelo grupo das ideias e modelos explicativos mais coerentes do ponto de vista científico. Tal processo permite desenvolver nos estudantes a compreensão de como se se processa a construção do conhecimento científico em uma comunidade científica.

Pérez (1993) afirma que quando os estudantes são envolvidos em atividades de investigação podem reconhecer problemas e usar estratégias pessoais, coerentes com os procedimentos da ciência, na sua resolução. Também podem desenvolver a capacidade para planejar experiências que permitam verificar uma hipótese, assim como usar a observação e acima de tudo apresentarem uma atitude crítica.

Para Gil-Perez (1993) as atividades de investigação devem apresentar características como: propor aos estudantes situações problemáticas abertas; favorecer a reflexão dos estudantes sobre a relevância das situações-problema apresentadas; permitir que os estudantes emitam hipóteses como atividade indispensável à investigação científica; elaborar um planejamento da atividade experimental; contemplar as implicações CTS do estudo realizado; proporcionar momentos para a comunicação do debate das atividades desenvolvidas.

Newman et al., (2004) afirmam que as atividades de investigação devem envolver o uso de evidência, lógica e imaginação na elaboração de explicações sobre o mundo natural. Esses pesquisadores salientam que quando os estudantes estão engajados em uma atividade investigativa, eles descrevem objetos e eventos, fazem perguntas, constroem explicações e expõem essas explicações para os demais estudantes.

Carvalho (2006) diz que uma atividade investigativa não pode se reduzir a uma mera observação ou manipulação de dados - ela deve levar ao estudante a refletir, a discutir, a explicar e a relatar seu trabalho aos colegas. Portanto, atividades de caráter investigativo devem: a) conter um problema (assim, a primeira preocupação do professor consiste em formular um problema que instigue e oriente o trabalho a ser desenvolvido com os estudantes); b) devem desencadear debates, discussões, outras atividades experimentais ou não; c) propiciar o desenvolvimento de argumentos, por meio de coordenação de enunciados teóricos e evidências, bem como considerar a multiplicidade de pontos de vista em disputa ou a serem coordenados; d) motivar e mobilizar os estudantes, promover o engajamento destes com o tema em investigação; e) propiciar a extensão dos resultados encontrados a todos os estudantes da turma.

Wellington (2000) nos coloca que as atividades de investigação devem ser pensadas, planejadas de diferentes maneiras variando o grau de abertura e de orientação. Algumas têm uma resposta correta, outras não. Algumas atividades podem demorar semanas ou meses, outras apenas minutos. Algumas envolvem situações abstratas, outras envolvem situações reais. Umas são atividades de resolução de problemas, outras não. Por outro lado, Ernest (1996) afirma que o conceito de investigação é problemático, primeiro porque descreve um processo: a ação de investigar, a procura, exame sistemático, inquisição, pesquisa personalizada e cuidadosa. Segundo porque trata de um processo gerador de novas questões, o que poderá alterar o foco da atividade, podendo ser um fator limitante da abordagem investigativa. 
São muitos as possibilidades e perspectivas de conceituar uma abordagem investigativa, mas o mais importante de nosso ponto de vista é compreender as diferentes possibilidades e perspectivas, bem como suas limitações que são coerentes com as perspectivas apresentadas por diferentes autores. Assim é possível considerar que a abordagem temática, a abordagem problematizadora, a abordagem CTS e a aprendizagem por problemas, entre outras, com diferentes possibilidades e com referenciais teóricos distintos parecem convergir para a "Pedagogia da Pergunta", ou seja, considerar que todo conhecimento é construído, elaborado, reelaborado na busca de respostas. De acordo com Bachelard (1996, p.18), todo o conhecimento deve se iniciar por uma pergunta, visto que ele é a própria resposta a uma pergunta ou como dizia Paulo Freire (FREIRE e FAUNDES,1985) "no ensino esqueceram-se das perguntas, tanto o professor como o aluno esqueceram-nas, e no meu entender todo conhecimento começa pela pergunta".

\section{Os fundamentos pedagógicos da abordagem investigativa}

Para iniciar uma discussão sobre alguns dos fundamentos pedagógicos das atividades investigativas (fazendo uso proposital do uso do termo atividades investigativas e não abordagem investigativa ou atividades de investigação por aceitar que mesmo com diferentes nomenclaturas e perspectivas todas convergem para um mesmo ponto, a pergunta), retomo o diálogo entre Paulo Freire e Antônio Faundes, em que Faundes diz: "Tenho a impressão (e não sei se você concorda comigo) de que hoje o ensino, o saber, é resposta e não pergunta" e Freire responde: "Exato, concordo contigo inteiramente! E isto que eu chamo de "castração da curiosidade". O que está acontecendo é um movimento unilinear, vai de cá para lá e acabou, não há volta, e nem sequer há uma demanda; o educador, de modo geral, já traz a resposta sem se Ihe terem perguntado nada!

Mas o que é perguntar? Como trabalhar em sala de aula com a pergunta, com a indagação, com a curiosidade? E, mais uma vez, retomo a fala de Freire: "a primeira coisa que aquele que ensina deveria aprender é saber perguntar". Assim, busca-se apresentar algumas perguntas que foram utilizadas em atividades nas salas de aula de química no sentido de buscar respostas, não necessariamente as respostas corretas ou mais coerentes, simplesmente a busca. Pedagogicamente a busca pelas respostas é um processo e, é nesse processo, que ocorre atividade intelectual.

No processo de ensino é fundamental saber elaborar perguntas. Para elaborar perguntas investigativas é necessário que estas sempre permitam uma relação entre conceito e contexto. Por exemplo, na pergunta: "Sabemos que existem hortênsias brancas, rosadas, lilases e azuis. Sabemos, também, que às vezes, ao longo do tempo, hortênsias rosadas se tornam azuis e vice-versa. Porque será que isso acontece? Se quisermos obter apenas hortênsias azuis ou apenas hortênsias rosadas o que devemos fazer? "Por que não devemos colocar um limão cortado ao meio emborcado sobre a pedra de mármore da pia da cozinha e nem derramar vinagre sobre ela?" (CHAVES e PIMENTEL, 2001). Nestas duas questões há uma relação entre o conceito e o contexto, pois o contexto remete ao conceito de $\mathrm{pH}$ e o conceito de $\mathrm{pH}$ remete à mudança de coloração das hortênsias, que por sua vez remete novamente ao conceito operacional de acidez e basicidade.

"Como saber o tempo de existência de um fóssil?" Também, nesta pergunta é possível identificar a relação entre o conceito e o contexto. Ou na simples pergunta "Todos os metais conduzem corrente elétrica?" Verifica-se que são questões investigativas em que 
as respostas não são simples. É necessário estabelecer sempre uma relação entre o contexto e o conceito na busca respostas a esta questão.

Se o objetivo de uma atividade é fazer com que o estudante aprenda, e que aprender ciências implica necessariamente em participar de algumas práticas dos cientistas, ou seja, um elemento central do contexto de produção do conhecimento científico. Os professores das universidades enquanto pesquisadores nos seus laboratórios, com seus grupos de pesquisas, em seus projetos sempre trabalham na perspectiva da pergunta, toda atividade, investigação ou projeto tem seu início na pergunta, mas, estes mesmo pesquisadores enquanto professores em suas salas de aula já trazem a resposta pronta, acabada, ou seja, ocorre apenas uma transmissão do conhecimento. Então, porque em suas salas de aulas não ocorrem atividades investigativas? O que os impede de atuar sem separar o professor do pesquisador investigador e o pesquisador investigador do professor?

Porque não considerar na elaboração de atividades investigativas tipologias de investigação (Quadro 1) semelhantes as propostas por Wellington (2000) que poderiam auxiliar o professor na elaboração e planejamento de atividades investigativas com seus estudantes.

Quadro 1. Tipologias de investigações.

\begin{tabular}{|c|c|}
\hline $\begin{array}{l}\text { Investigações do tipo } \\
\text { "qual?" }\end{array}$ & $\begin{array}{c}\text { - Qual dos fatores afeta X? } \\
\text { • Qual é o melhor plano para...? } \\
\text { • Qual o X melhor para...? }\end{array}$ \\
\hline $\begin{array}{l}\text { Investigações do tipo "o } \\
\text { quê?" }\end{array}$ & $\begin{array}{c}\text { • O que acontece se...? } \\
\text { • Que relação existem entre X e Y? }\end{array}$ \\
\hline $\begin{array}{l}\text { Investigações do tipo } \\
\text { "como?" }\end{array}$ & $\begin{array}{c}\text { - Como é que diferentes } X \text { afetam } Y \text { ? } \\
\text { - Como é que varia } X \text { com } Y \text { ? } \\
\text { - Como é que } X \text { afeta } Y \text { ? }\end{array}$ \\
\hline Investigações Gerais & $\begin{array}{c}\text { - Um questionário histórico ou local } \\
\text { - Um projeto a longo prazo }\end{array}$ \\
\hline $\begin{array}{l}\text { Atividades de resolução de } \\
\text { problemas }\end{array}$ & $\begin{array}{c}\text { - Planejar e construir } \\
\text { - Resolver um problema prático } \\
\text { • Simulações }\end{array}$ \\
\hline
\end{tabular}

Adaptado e traduzido de Wellington (2000).

Wellington (2000) aponta que a abordagem investigativa deve apresentar pelo menos três etapas: i) os estudantes colocam questões, elaboram um plano, fazem previsões e apresentam hipóteses; ii) observam, medem e manipulam variáveis; iii) analisam e interpretam os resultados e avaliam evidências científicas. Mas, ressalta que o processo de interpretar e avaliar os resultados não é a última fase, podendo-se voltar a colocar novas questões, rever o plano e fazer novas previsões.

Retomando ao que consideramos o fundamento pedagógico da abordagem investigativa, a pergunta, afirmamos que no caso particular do ensino de ciências, o conhecimento científico não pode ser reduzido apenas ao conhecimento de fatos e conceitos. É fundamental, pois, que os estudantes, gradativamente, desenvolvam um entendimento da natureza das explicações, dos modelos e das teorias científicas, bem como das práticas utilizadas para gerar esses produtos e, isso só será possível se forem ativos no processo de elaboração conceitual. Portanto, a abordagem investigativa apresenta possibilidades de também discutir a natureza da ciência nas atividades em sala de aula, além de colocar o estudante frente a resolução de um problema, ou seja, a pensar. Pois pensar é parte do processo de solucionar problemas incluindo o reconhecimento do 
problema e de ações necessárias a resolver o problema. Acima de tudo, o pensar faz com que o estudante construa seus próprios modelos explicativos contribuindo para que exerça uma autonomia no processo de aprendizagem.

Uma abordagem investigativa deve engajar os estudantes não apenas em um trabalho experimental, manual, mas principalmente intelectual. Acima de tudo em uma abordagem investigativa, o estudante deve manipular ideias. Em outras palavras, o que se espera é que a expressão "participação ativa dos estudantes", tantas vezes usada para justificar o uso de atividades investigativas nas aulas de ciências, passe a adquirir o significado de "participação intelectualmente ativa dos estudantes".

Pedagogicamente, uma abordagem investigativa deve partir de situações problemas que mobilizem os estudantes a participarem da investigação, suscitando a busca de informações, a elaboração de modelos explicativos sobre fenômeno em estudo, o contraste dos modelos, e a discussão dos resultados para a elaboração de conclusões acerca do problema. É fundamental que na abordagem investigativa os estudantes mobilizam os conhecimentos que já têm e busquem outros para propor modelos explicativos de modo a solucionarem o problema.

Mas, para que atividades investigativas ocorram em sala de aula é fundamental o papel do professor. Para Carvalho (1995) é o professor que propõe problemas a serem resolvidos, que irão gerar ideias, modelos explicativos que, sendo discutidas, permitirão a ampliação e reformulação dos modelos. É o professor o responsável por estabelecer a reflexão e apresentar novas evidências no processo investigativo, afinal é o professor que faz a pergunta, ou aquele que proporciona as condições necessárias na busca das respostas.

\section{Limites e possibilidades de atividades investigativas em aula de química}

Na perspectiva em que foram realizadas as reflexões sobre os fundamentos teóricos e pedagógicos da abordagem investigativas é possível apresentar fatores que influenciam a realização de atividades de investigativas (possibilidades) e fatores que dificultam (limites). Como possibilidades, podemos apresentar, por exemplo, a possibilidade de proporcionar momentos de discussões, de ajudar os estudantes a relacionarem o conceito com o contexto dentro e fora da escola e, o mais importante, de participação intelectualmente ativa na atividade. Como limites da abordagem investigativa podemos colocar três fatores: professor, materiais e estudantes. Mas, se for sintetizar podemos chegar que todas as limitações passam pelo processo de formação de professores de ciências, das concepções de ciências, da natureza da ciência e de concepções de ensino e aprendizagem. De certa forma o processo de formação de professores se apresenta como o principal fator limitante visto que, mesmo em escolas que tem laboratório de ciências bem equipados, são pouco ou quase nunca utilizados. Também, há atividades investigativas que não necessitam do uso de laboratórios.

Nas salas de aula de ciências o que mais vê-se é o professor fazendo anotações no quadro, seguidas de explicações e os estudantes anotando e ouvindo-o dissertar sobre um determinado tópico de conteúdo ou conceito. Mas, pergunta-se de onde vem esta prática? Será que em seus cursos de formação estes professores vivenciaram atividades investigativas? Os cursos de formação de professores que seguem modelos rígidos, 
previamente definidos não limitam a formação de professores investigativos? Numa perspectiva crítica ao se analisar o perfil do professor de ciências que são formados nos cursos de licenciatura, a partir das concepções dos professores formadores, principalmente na área de Ciências da Natureza, classificamos tais práticas como tradicionais. Isso pode ser devido às aulas tradicionais da formação inicial, pois conforme destaca Maldaner (1998) torna-se necessário romper com a formação que os professores tiveram centrada na transmissão de conhecimentos, ou seja, uma formação inicial trabalhada de forma reprodutivista e tradicional sem experiências investigativas ou problematizadoras em sua formação. Sendo que para transformar essa realidade demanda tempo.

Entretanto, não devemos colocar toda a responsabilidade sobre os professores que enfrentam uma série de desafios na educação brasileira. Assim, há outras causas limitantes de um trabalho na perspectiva da abordagem investigativa como a precariedade estrutural das escolas e a baixa renumeração profissional que embarca toda a problemática da falta de tempo decorrente da necessidade de trabalhar várias horas e em diferentes escolas, o que impossibilita a compra de materiais e o tempo de planejamento de forma autônoma pelos professores.

Portanto, as possibilidades e potencialidades da abordagem investigativa no Ensino de Ciências só será possível quando os formadores de professores, que na sua grande maioria são pesquisadores, trabalharem em suas disciplinas na perspectiva da pergunta, assim como fazem em seus grupos de pesquisa.

\section{Referencias}

AULER, D; BAZZO, W. A. Reflexões para a Implementação do Movimento CTS no Contexto Educacional Brasileiro. Ciência \& Educação. v. 7, n. 1, p. 1-13, 2001.

AULLS, M.; SHORE, B. Inquiry in education: The conceptual foundations for research as a curricular imperative. New York, NY: Lawrence Erlbaum associates, 2008.

BACHELARD, G. O novo espírito científico: contribuição para uma psicanálise do conhecimento. Tradução Estrela dos Santos Abreu. Rio de Janeiro: Contraponto, 1996.

BRASIL, Base Nacional Comum Curricular. Ministério da Educação. Brasília, 2016.

BORGES, A. T. Novos rumos para o laboratório escolar de ciências. Caderno Brasileiro. Ensino de Física. v. 19, n.3: p.291-313, 2002.

BRASIL. Ministério da Educação. PCN+ Ensino Médio: Orientações educacionais complementares aos Parâmetros Curriculares Nacionais - Ciências da Natureza e suas Tecnologias. Secretaria de Educação Média e Tecnológica: MEC; SEMTC, 2002

BRASIL. Ministério da Educação. PCNEM - Parâmetros Curriculares Nacionais. Secretaria de Educação Média e Tecnológica: MEC; SEMTC, 1999.

BRASIL. Ministério da Educação. PCN de Ciências naturais para a $5^{\mathrm{a}}$ a $8^{\mathrm{a}}$ séries, Brasília, Brasil, 1998;

CACHAPUTZ, A. A necessária renovação do ensino de ciências. São Paulo: Cortez, 2005.

CARVALHO, A. M. P. Las practices experimentales en el proceso de enculturación cientifica . In: GATICA, M Q; ADÚRIZ-BRAVO, A (Ed). Enseñar ciencias en el Nuevo milenio: retos e propuestas. Santiago: Universidade católica de Chile.2006. 
CARVALHO, A. M. P.; GIL, D. Formação de professores de ciências: tendências e inovações. 2. ed. São Paulo: Cortez / Coleção questões da nossa época, 1995. 120 p.

CARVALHO, Anna Maria Pessoa de. Anna Maria Pessoa de Carvalho (org.), O Ensino de Ciências: unindo a pesquisa e a prática. São Paulo. 2004.

CHAVES, M. H. O., PIMENTEL, N. L. Uma proposta metodológica para o ensino de ácidos e bases numa abordagem problematizadora. UFSM - Santa Maria/RS - 2001.

DELIZOICOV, D. Ensino de Física e a concepção freiriana de educação. Revista de Ensino de Física, v. 5, n. 2, p. 85-98, 1983.

ERNEST, P. Investigações, resolução de problemas e pedagogia. In ABRANTES, P.; CUNHA LEAL, L.; PONTE, J. P. (Eds.). Investigar para aprender matemática. Lisboa: Projecto matemática para todos e associação de professores de matemática. 1996.

FREIRE, P.; FAUNDEZ, A. Por uma Pedagogia da Pergunta. Rio e Janeiro: Paz e Terra, 1985. (Coleção Educação e Comunicação: v. 15)

GIL, D. Contribuición de la historia y de la filosofiade las cienciasal dessarollo e um modelo de enseñanza/aprendizajecomo investigación. Enseñanza de las ciências, 11(2), 1993

HODSON, D. Hacia un enfoque más critico del trabajo de laboratorio. Enseñanza de lãs Ciencias, 1994.

LEDERMAN, N.G. Relating teaching behavior and classroom climate to changes in students' conceptions of the nature of science. Science Education, 70(1), pp. 3-19,1986.

LEDERMAN, N.G. Students' and teachers' conceptions of the nature of science: A review of the research. Journal of Research in Science Teaching, 29(4), pp. 331-359, 1992.

MALDANER, O. A. A Formação do Professor Pesquisador: a pesquisa do professor como prática de formação continuada. In: Anais do VI Seminário Internacional de Alfabetização e Educação Científica. Unijuí, 1998.

NEWMAN Jr. W. J; ABEL. S. K, HUBBARD. P. D; MC DONALD. J. Dilemmas of teaching inquiry in elementary science methods. Journal of Science Teacher Education 15(4), 2004.

PEDUZZI,L.O.Q.; MOREIRA,M.A. Solução de problemas em Física: um estudo sobre o efeito de uma estratégia. Revista Brasileira de Física, (4):1067-1083, 1981.

SÁ, E.F. Discursos de professores sobre ensino de ciências por Investigação. Tese de DoutoradoBelo Horizonte: UFMG/FaE, 2009.

SHULMAN, L.S. Renewing the pedagogy of teacher education: The impact of subject-specific conceptions of Teachers' teaching, en Montero, M.L. y Vez, J.M. (eds.), Las didacticas especqicas en la formación del profesorado, pp. 53-69, 1993.

SHULMAN, L.S. Paradigms and Research programs in the study of teaching: A contemporary perspective. Versión española de 1989. Paradigmas y programas de investigación en el estudio de la enseñanza: una perspectiva contemporinea en Wittrock, La investigación de la enseñanza, I. Enfoques, teorías y rnétodos. Barcelona: Paidós, 1986.

WELLINGTON, J. Re-thinking the Role of Practical Work in Science Education. In M. Sequeira, L. Dourado, M.T. Vilaça, S. Afonso \& J. M. Baptista (Orgs.) Trabalho Prático e Experimental na Educação em Ciências, 19-28. Braga: Universidade do Minho, Departamento de Metodologias da Educação. 2000. 